\title{
Proliferation and Death of Oligodendrocytes and Myelin Proteins Are Differentially Regulated in Male and Female Rodents
}

\author{
Mirela Cerghet, ${ }^{1,2}$ Robert P. Skoff, ${ }^{2}$ Denise Bessert, ${ }^{2}$ Zhan Zhang, $^{2}$ Chadwick Mullins, ${ }^{2}$ and M. Said Ghandour ${ }^{3}$ \\ ${ }^{1}$ Department of Neurology, Henry Ford Hospital, Detroit, Michigan 48202, ${ }^{2}$ Department of Anatomy and Cell Biology, Wayne State University School of \\ Medicine, Detroit, Michigan 48201, and ${ }^{3}$ Institut de Physique Biologique, Unité Mixte de Recherche 7004, Strasbourg 67085, France
}

\begin{abstract}
Sexual dimorphism of neurons and astrocytes has been demonstrated in different centers of the brain, but sexual dimorphism of oligodendrocytes and myelin has not been examined. We show, using immunocytochemistry and in situ hybridization, that the density of oligodendrocytes in corpus callosum, fornix, and spinal cord is $20-40 \%$ greater in males compared with females. These differences are present in young and aged rodents and are independent of strain and species. Proteolipid protein and carbonic anhydrase-II transcripts, measured by real-time PCR, are approximately two to three times greater in males. Myelin basic protein and $2^{\prime}, 3^{\prime}$-cyclic nucleotide $3^{\prime}$-phosphodiesterase, measured by Western blots, are 20-160\% greater in males compared with females. Surprisingly, both generation of new glia and apoptosis of glia, including oligodendrocytes, are approximately two times greater in female corpus callosum. These results indicate that the lifespan of oligodendrocytes is shorter in females than in males. Castration of males produces a female phenotype characterized by fewer oligodendrocytes and increased generation of new glia. These findings indicate that exogenous androgens differentially affect the lifespan of male and female oligodendrocytes, and they can override the endogenous production of neurosteroids. The data imply that turnover of myelin is greater in females than in males. $\mu$-Calpain, a protease upregulated in degeneration of myelin, is dramatically increased at both transcriptional and translational levels in females compared with males. These morphological, molecular, and biochemical data show surprisingly large differences in turnover of oligodendrocytes and myelin between sexes. We discuss the potential significance of these differences to multiple sclerosis, a sexually dimorphic disease, whose progression is altered by exogenous hormones.
\end{abstract}

Key words: oligodendrocyte; myelin; sexual dimorphism; proliferation; apoptosis; estrogen; estradiol

\section{Introduction}

The concept of sexual dimorphism in the brain was first demonstrated in 1976 by Nottebohm and Arnold in the vocal control area of the songbird (Nottebohm and Arnold, 1976). These researchers correlated differences in sexual behavior with anatomical sexual dimorphism, demonstrating a larger and more complex neural circuitry in males than in females. The avian studies prompted investigators to examine sexual dimorphism in mammals. Predictably, in humans and in rodents, numerous studies have demonstrated sexual dimorphism in the hypothalamus, a center for regulating reproductive functions (Mong et al., 1999). Less predictably, anatomical differences have been demonstrated in many different gray matter regions of the CNS. Hippocampal neurons in males have a larger dendritic tree than females (Barrera et al., 2001). This structure, under the influence of sex hormones (Roof, 1993), has been postulated to play a role in spatial

Received June 1, 2005; revised Dec. 19, 2005; accepted Dec. 20, 2005.

This work was supported by National Multiple Sclerosis Society Grant RG-3449. M.C. was supported by Wayne State University Graduate School, and data generated by M.C. were used as partial fulfillment for the PhD degree.

Correspondence should be addressed to Robert P. Skoff, Department of Anatomy and Cell Biology, Wayne State University School of Medicine, 540 East Canfield, Detroit, Ml 48201. E-mail: rskoff@med.wayne.edu.

DOI:10.1523/JNEUROSCI.2219-05.2006

Copyright $\odot 2006$ Society for Neuroscience $\quad$ 0270-6474/06/261439-09\$15.00/0 learning (Sherry et al., 1992). Using magnetic resonance imaging, morphological differences have been reported in cortical gray matter volume (Gur et al., 1999). Human females have a greater volume of gray matter associated with language functions (Schlaepfer et al., 1995; Harasty et al., 1997), whereas males have greater volumes in amygdala, frontomedial cortex, and hypothalamus relative to total cerebral size (Goldstein et al., 2001). The direct action of different male and female sex hormones on these sexually dimorphic brain centers is a likely explanation for these differences.

Reports of sexual dimorphism in white matter are limited to gross anatomical differences and numbers of myelinated axons. White matter volume (Gur et al., 1999), especially in the corpus callosum (Fitch et al., 1990), is increased in males, and the number of myelinated axons in the splenium of rat corpus callosum in males is greater than in females (Kim and Juraska, 1997). Similar differences were found in the genu of corpus callosum (Mack et al., 1995), with females having more unmyelinated fibers than males. These differences were attributed to difference in levels of steroid hormones affecting myelination (Nuñez et al., 2000).

The studies described above hint that the volume of myelin is less and fewer oligodendrocytes (Olgs) are present in females compared with males. However, no cellular, biochemical, or 
physiological differences have been reported between male and female Olgs. In our histological and immunocytochemical studies of neuroglia in the spinal cord, we suspected apparent differences in numbers of neuroglia between males and females (Knapp et al., 1996) but never quantified these observations. Recently, we showed that the estrogen receptors (ERs) $\alpha$ and $\beta$ were expressed in Olgs in vitro and $\mathrm{ER} \beta$ is expressed in Olgs and myelin in vivo (Zhang et al., 2004), lending additional support to our hypothesis that hormones regulate numbers and functions of Olgs. We first quantified the number of Olgs in males and females and found dramatic differences in the number of Olgs. We pursued these findings to find major molecular and biochemical differences between the sexes. These findings, never suspected, may provide answers in understanding the etiology of demyelinating diseases and aging.

\section{Materials and Methods}

Animals. Nine-month-old C57BL/6J male and female (The Jackson Laboratory, Bar Harbor, ME), 13- to 15-month-old B6CBA (The Jackson Laboratory), 22- to 23-month-old C57BL/6J (National Institute on Aging, Bethesda, MD), and 6-week-old CDIRS (Charles River Laboratories, Wilmington, MA) rats were used for immunocytochemistry and in situ hybridization. Nine-month-old C57BL/6J (The Jackson Laboratory) were used for Western blot and reverse transcription (RT)-PCR. Sixmonth-old C57BL/6J male mice were castrated (Harlan Sprague Dawley, Indianapolis, IN) and permitted to live for another 3 months until used for carbonic anhydrase-II (CA II) and bromodeoxyuridine (BrdU) immunocytochemistry. All mice and rats were injected with a lethal dose of chloral hydrate $(650 \mathrm{mg} / \mathrm{kg}$ body weight $)$ in accordance with Wayne State University Department of Laboratory Animal Resources protocols.

Immunocytochemistry and in situ hybridization. All rodents were perfused intracardially with a $4 \%$ solution of paraformaldehyde in PBS. Forty micrometer vibratomed sections were routinely prepared (Cerghet et al., 2001), and immunohistochemistry was performed as described previously using polyclonal antibodies to CA II (Ghandour and Skoff, 1991) diluted 1:400 and cleaved caspase-3 (Cell Signaling Technology, Beverly, MA) diluted 1:50, followed by colorimetric detection with diaminobenzidine (DAB) (Sigma, St. Louis, MO). For BrdU immunocytochemistry, animals were intraperitoneally injected with BrdU (Sigma), $100 \mu \mathrm{g} / \mathrm{g}$ body weight, for 3 consecutive days and killed 1 week after the first injection. Six to eight matched brain sections at the level of striatum were washed overnight in PBS, incubated in $2 \mathrm{~N} \mathrm{HCl}$ at $37^{\circ} \mathrm{C}$ for $30 \mathrm{~min}$, washed two times in $0.1 \mathrm{M}$ sodium borate, $\mathrm{pH} 8.3$, at room temperature for $30 \mathrm{~min}$, and incubated with a mouse monoclonal anti-BrdU (1:100; Becton Dickinson, Franklin Lakes, NJ). Expression was visualized with a goat anti-mouse IgG fluorophore (Alexa Fluor 564; Invitrogen, Carlsbad, CA). For immunoperoxidase double labeling, anti-BrdU followed by anti-mouse IgG HRP diluted 1:200 (Amersham Biosciences, Piscataway, $\mathrm{NJ}$ ) and DAB with metal enhancer was first used, and then polyclonal anti-GFAP (1:100; Sigma) or anti-CA II followed by anti-rabbit IgG (1: 100; Amersham Biosciences) and DAB were applied. Double immunofluorescence was also performed using anti-cleaved caspase-3 (Cell Signaling Technology) antibody and then AOO7 (Bansal et al., 1992), followed by a mixture of goat anti-rabbit rhodamine (Roche Diagnostics, Indianapolis, IN) and goat anti-mouse IgM FITC. Three to four brain and spinal cord sections per animal were matched at the same level and processed for in situ hybridization using established laboratory procedures (Bessert and Skoff, 1999) with proteolipid protein (PLP) cDNA clone 68 (Sorg et al., 1987) kindly provided by A. T. Campagnoni (University of California, Los Angeles, Los Angeles, CA). Sections were rinsed and mounted. Controls for all immunocytochemistry staining consisted of sections in which primary antibody was not applied.

Microscopy. For each animal, four to five matched sections were counted on both right and left sides, using a Leitz (Wetzlar, Germany) Laborlux microscope, equipped with a $10 \mathrm{~mm}^{2}$ grid in the eyepiece. Positive cells were counted with a $25 \times$ objective and $10 \times$ eyepiece, using a $1 \mathrm{~cm}^{2}$ grid overlying the corpus callosum adjacent to the lateral ventri- cle at the level of striatum, tip of the fornix at rostral hippocampus, and ventral funiculus of spinal cord adjacent to ventromedial fissure. Only Olgs whose nuclei were visible in the sections were counted by focusing up and down with the fine adjustment. The diameter of Olg nuclei in males and females was not different, permitting direct comparison of raw numbers between the sexes (Guillery and Herrup, 1997). The numbers of cells counted on the $1 \mathrm{~cm}^{2}$ grid were reported as number of cells per 1 $\mathrm{mm}^{2}$ and corrected for the lens magnification. At each time point, for each structure and each sex, a minimum of 5600 and a maximum of 10,400 Olgs were counted. Quantification of Olgs using CA II immunocytochemistry or PLP in situ hybridization was blindly counted. Animal identification on the slide was covered with tape before being counted by the first author. The number of Olgs in several blinded sections were also counted by two other authors, and the variation between the three different investigators was within $6 \%$. The slides used for the BrdU-positive $\left(\mathrm{BrdU}^{+}\right)$cell counts were not masked because the number of $\mathrm{BrdU}^{+}$ cells in the subventricular zone of females is many times that of males, permitting immediate identification of the sex.

Western blotting. After cervical dislocation, brain and cervical spinal cord were dissected, homogenized, and lysed in suspension buffer $(0.1 \mathrm{M}$ $\mathrm{NaCl}, 0.01$ м Tris- $\mathrm{HCl}, 0.001$ м EDTA, $5 \mu \mathrm{g} / \mathrm{ml}$ aprotinin, and $100 \mu \mathrm{g} / \mathrm{ml}$ phenylmethylsulfonyl fluoride). An equal volume of homogenized brain or spinal cord and $2 \times$ SDS (with $0.03 \mathrm{~g} / \mathrm{ml}$ dithiothreitol) were mixed and sonicated for $30 \mathrm{~s}$. Total protein concentration was measured using an Eppendorf (Westbury, NY) BioPhotometer. Blots were incubated with mouse anti-myelin basic protein (MBP) diluted 1:1000, (SMI94; Sternberger Monoclonals, Lutherville, MD), anti $2^{\prime}, 3^{\prime}$-cyclic nucleotide 3'-phosphodiesterase (CNPase) diluted 1:1000 (Chemicon, Temecula, CA), anti-calpain-I diluted 1:1000 (Chemicon), or rabbit anti-CA II diluted 1:1000, followed by incubation with anti-mouse IgG HRP (1:5000) or anti-rabbit HRP (1:5000), and were developed with the ECL kit (Amersham Biosciences). All blots were stripped and reprobed for $\beta$-actin for optical density analyses that were performed using ImageQuant (Molecular Dynamics, Sunnyvale, CA) or Adobe Photoshop (Adobe Systems, San Jose, CA).

$R T-P C R$. Total RNA was isolated from the brains using TRIzol reagent (Invitrogen), and cleaned with Dnase1 (Amersham Biosciences) following the instructions of the manufacturer. To test for potential DNA contamination, aliquots of RNA were directly used in a PCR reaction in a Hybaid PCR Express (Thermo Electron Corporation, Waltham, MA) with primers that detect genomic DNA for PLP gene (Nave et al., 1987). The RT product was generated using the Qiagen (Valencia, CA) Omniscript kit, following the instructions of the manufacturer. For PLP/DM20 amplification, Ready-to-Go PCR beads (Amersham Biosciences) were used with a forward exon 2 primer (5'-GCTAATTGAGACCTATTTCTCC) and reverse exon 6 primer (5'-AGCAATAAACAGGTGGAAGGTC) (Invitrogen) or, for carbonic anhydrase-II, forward primer (5'-ATGTCCCACCACTGGGATA) and reverse primer (5'ACGCTTTGATCTTTCTATTCTT) (Invitrogen). Aliquots without RT product were used as controls.

Real-time PCR. RT was obtained as described above and subjected to real-time PCR in the presence of SYBR Green I dye (BioWhittaker, Rockland, ME) and CA II primers, PLP III primers, specific for PLP and not for DM20 (forward exon 3, 5' -AAGGGGAGGGGTTCCAGAGG-3'; reverse from exon 3 and extending into exon 4, 5'-AGGGCATAGGTGATGCCCAC- $3^{\prime}$ ) (Invitrogen), $\mu$-calpain primers designed from the large subunit domain III (sense, $5^{\prime}$-TCTCTCTGAAGAGGAGATTGA3'; antisense, 5' - CCAGCCGCACAAGACAGCA-3') (Invitrogen), and glyceraldehyde-3-phosphate dehydrogenase (GAPDH) primers (sense, 5'-AAGGTCATCCCAGAGCTGAA-3'; antisense, 5'-GCCATGAGGTCCACCACCCT-3') (Invitrogen) (Daston et al., 1996). The primers for 18 S were from the Quantum RNA Universal 18S primer kit (Ambion, Austin, TX).

The amplification profiles were as follows: for $18 \mathrm{~S}, 40$ cycles at $95^{\circ} \mathrm{C}$ for $15 \mathrm{~s}, 57^{\circ} \mathrm{C}$ for $15 \mathrm{~s}, 72^{\circ} \mathrm{C}$ for $15 \mathrm{~s}$; for CA II, GAPDH, and PLP, 40 cycles at $95^{\circ} \mathrm{C}$ for $15 \mathrm{~s}, 60^{\circ} \mathrm{C}$ for $30 \mathrm{~s}, 72^{\circ} \mathrm{C}$ for $15 \mathrm{~s}$; and for $\mu$-calpain, 40 cycles at $95^{\circ} \mathrm{C}$ for $15 \mathrm{~s}, 63^{\circ} \mathrm{C}$ for $30 \mathrm{~s}, 72^{\circ} \mathrm{C}$ for $15 \mathrm{~s}$ in a Smart Cycler (Cepheid, Sunnyvale, CA). Product identity was confirmed by electrophoresis and 

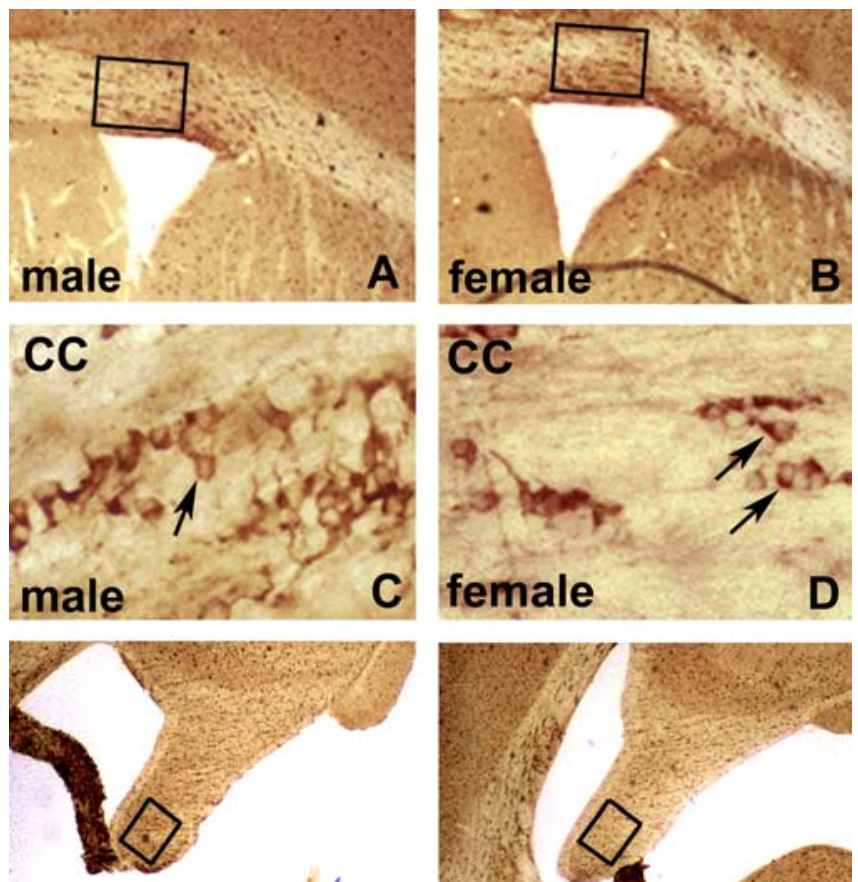

male
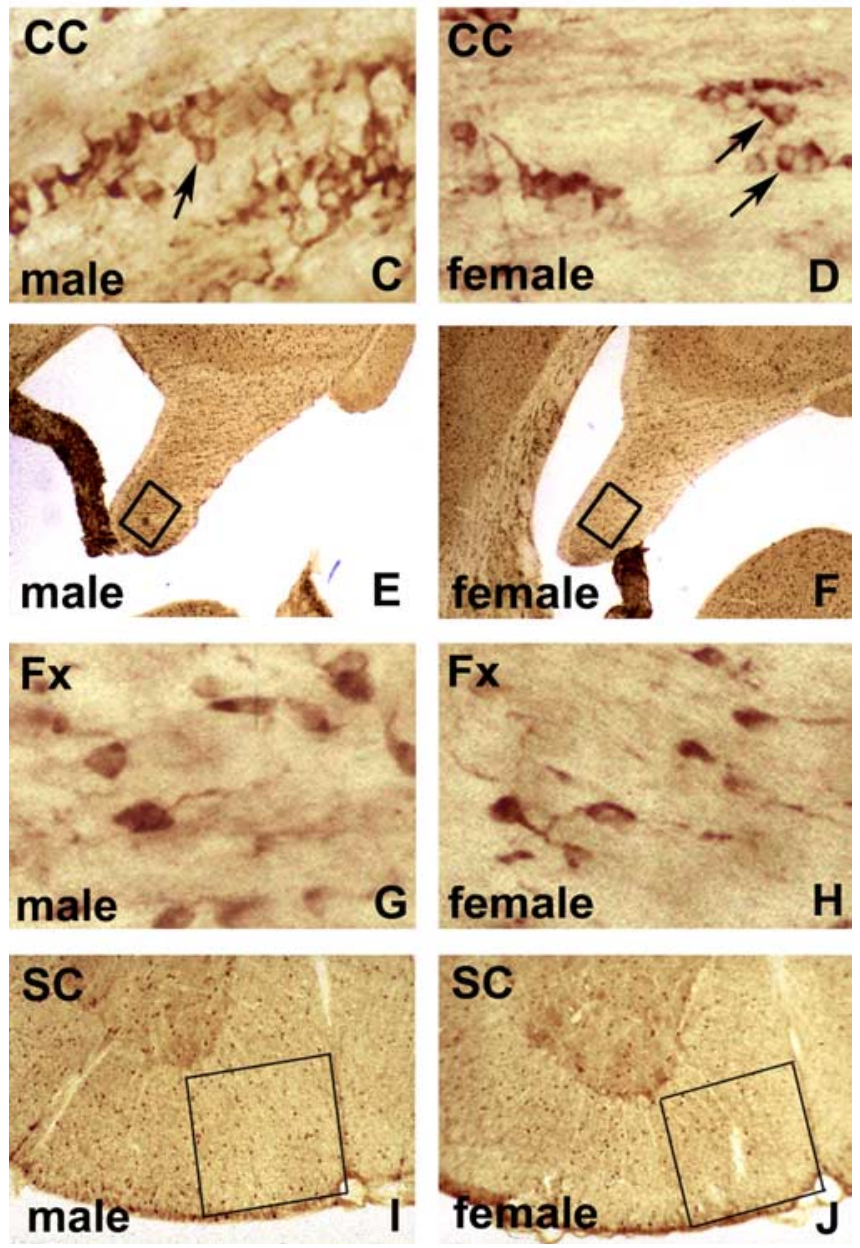

Figure 1. Carbonic anhydrase Il immunoperoxidase staining of vibratomed sections of corpora callosa $(\boldsymbol{A}-\boldsymbol{D})$, fornices $(\boldsymbol{E}-\boldsymbol{H})$, and spinal cords $(\boldsymbol{I}, \boldsymbol{J})$ of 22-month-0ld $(57 \mathrm{BL} / 6 \mathrm{~J}$ mice. Low magnification of male $(\boldsymbol{A})$ and female $(\boldsymbol{B})$ corpora callosa $(C C)$ at striatal levels shows boxed areas used for quantification of $\mathrm{CA}$ II cells. Higher magnification illustrates immunostained $\mathrm{Olg}$ cytoplasm (arrows) in males $(\boldsymbol{C}$ and females $(\boldsymbol{D})$. Olgs were counted as positive that have unstained nuclei surrounded by cytoplasmic staining. Olgs are typically arranged in rows, interspersed with astrocytes. Low magnification of male $(\boldsymbol{E})$ and female $(\boldsymbol{F})$ fornices $(\mathrm{Fx})$ shows boxed areas used for quantification. Higher magnification shows cytoplasmic Olg immunostaining in male $(\boldsymbol{G})$ and female $(\boldsymbol{H})$. Low magnification of spinal cord (SC) ventral funiculus adjacent to ventral fissure shows boxed areas used for quantification in male $(\boldsymbol{I})$ and female $(\boldsymbol{J})$ mice.

by melting-point analysis. GAPDH and $18 \mathrm{~S}$ primers were used as internal controls to calculate the amount of total cDNA subject to amplification.

\section{Results}

Density of oligodendrocytes

We quantified the number of Olgs in selected white matter tracts in the brain and spinal cord of male and female rodents ranging from 6 to 22 postnatal weeks. Low-magnification micrographs (Figs. 1,2) show that sections are evenly stained and lack tears, providing consistent material for quantification. The number of
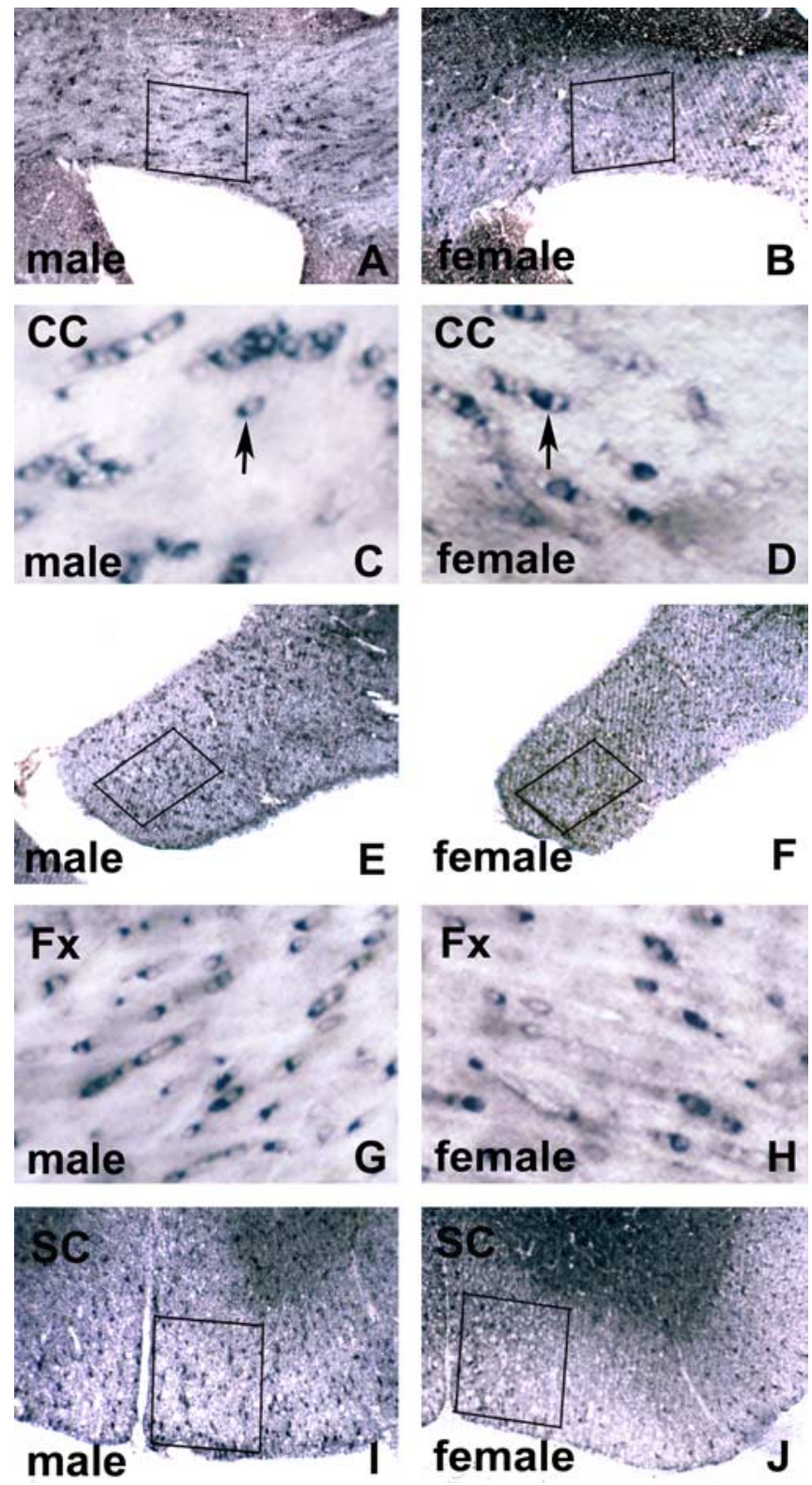

Figure 2. In situ hybridization staining using digoxigenin-labeled PLP/DM20 CDNAs of corpora callosa $(\boldsymbol{A}-\boldsymbol{D})$, fornices $(\boldsymbol{E}-\boldsymbol{H})$, and cervical spinal cord $(\boldsymbol{I}, \boldsymbol{J})$ at the striatal level of 22month-old $557 \mathrm{BL} / 6 \mathrm{~J}$ mice. Low magnification of male $(\boldsymbol{A})$ and female $(\boldsymbol{B})$ corpora callosa $(C \mathrm{C})$ at striatal levels shows boxed areas used for quantification. Higher magnification of male $(\boldsymbol{C})$ and female (D) corpora callosa shows staining of Olg cytoplasm (arrows). Olgs were counted as positive that have perinuclear cytoplasm staining denoting the presence of PLP mRNA. Low magnification of male $(\boldsymbol{E})$ and female $(\boldsymbol{F})$ fornices $(\mathrm{Fx})$ showing boxed areas used for quantification. Higher magnification shows cytoplasmic $0 \mathrm{lg}$ immunostaining in males $(\boldsymbol{G})$ and females $(\boldsymbol{H})$. Low magnification of spinal cord (SC) ventral funiculus shows boxed area used for quantification in male $(\boldsymbol{I})$ and female $(\boldsymbol{J})$ mice.

Olgs was counted with an antibody directed against CA II that we have previously shown specifically stains Olgs and not astrocytes (Ghandour et al., 1979; Jalabi et al., 2003) (Fig. 1). Additionally, PLP/DM20 mRNA expression was visualized in Olgs using a nonradioactive in situ hybridization method (Bessert and Skoff, 1999) (Fig. 2). Both CA II and PLP/DM20 message are localized to the Olg perikarya and do not stain myelin, allowing Olg cell bodies to distinctly stand out against the background (Figs. $1 C, D, G, H, 2 C, D, G, H)$. Both staining procedures produced similar quantitative results. $\mathrm{CA} \mathrm{II}^{+} / \mathrm{PLP}^{+}$cells were counted in (1) 
the corpus callosum superior to the lateral ventricle (Figs. $1 A, B$, $2 A, B)$, (2) the tip of fornix at the rostral hippocampus (Figs. $1 E, F, 2 E, F)$, and (3) the ventral funiculus of cervical spinal cord (Figs. $1 I, J, 2 I, J$ ). Cells were counted directly through the microscope at a magnification of $250 \times$ using a $1 \mathrm{~cm}$ grid divided into 100 squares (for details, see Materials and Methods). The difference in Olg cell numbers is obvious at higher magnifications. In Figure 2, $C$ and $D$, the number of Olgs counted in the males is 23 and in the females 16; in Figure 2, $G$ and $H$, the number of Olgs counted in the males is 37 and in the females 22 . The number of $\mathrm{CA} \mathrm{II}^{+}$cells and $\mathrm{PLP}^{+}$cells is significantly greater in males at all ages and in all structures (Fig. 3). In the corpus callosum of mice, the percentage increase in CA II ${ }^{+}$Olgs in males compared with females in mice range from a high of $35 \%$ at 9 months to a low of $18 \%$ at 22 months (Fig. $3 B$ ). In the fornix of mice, the percentage increase in $\mathrm{CA} \mathrm{II}^{+}$Olgs in males compared with females range from a high of $34 \%$ at 9 months to a low of $20 \%$ at 22 months (Fig. $3 D)$. In the ventral funiculus of the cervical spinal cord of mice, the percentage increase in $\mathrm{CA} \mathrm{II}^{+}$cells range from a high of $30 \%$ at 13 months to a low of $14 \%$ at 22 months (Fig. $3 F$ ). In corpus callosum and fornix of 6-week-old rats, the percentage increase for CA II is, respectively, 33 and $40 \%$.

In the corpus callosum of mice, the percentage increase in PLP/DM20 ${ }^{+}$cells is $30 \%$ at 13 and 22 months (Fig. $3 H$ ). In the fornix of mice, the percentage increase in PLP/DM $20^{+}$cells is 30 and $35 \%$ at 13 and 22 months, respectively (Fig. $3 J$ ). In the spinal cord of mice, the percentage increase in PLP/DM20 ${ }^{+}$cells is 31 and $37 \%$ at 13 and 22 months, respectively. At $13-15$ months, the percentage increases for both CA II and PLP/DM20 cells are virtually the same in each of the three structures. At 22-23 months, $\sim 10 \%$ more $\mathrm{PLP}^{+}$than $\mathrm{CA} \mathrm{II}{ }^{+}$cells are counted in corpus callosum, fornix, and spinal cord. The reduction in the number of $\mathrm{CA} \mathrm{II}^{+}$cells in older animals is likely technical, because we found less penetration of Olg and myelin antibodies in aged animals, and white matter immunostaining is less consistent in the older animals. Although we cannot state the precise increase in Olgs of males compared with females in the 2-year-old mice, it is at least $15 \%$ based on the CA II immunostaining and may be as high as $35 \%$ based on the PLP in situ hybridization. At 13-15 months, the percentage increases for both in situ hybridization and immunocytochemical values are very close and show a 30\% greater density of Olgs in males compared with females.

\section{Gene and protein expression in oligodendrocytes}

The increase in the number of Olgs in males suggests that Olg and myelin-specific proteins and genes might likewise be increased. MBP constitutes $40 \%$ of myelin protein (Benjamins and Morell, 1978), and its four major isoforms are reliably detected with Western blot (supplemental Fig. S1, available at www.jneurosci.org as supplemental material). Total MBP protein levels, obtained by summing all four isoforms, are 20 and 25\% greater in 9-month-old male brains and spinal cords, respectively, compared with females (Fig. 4). These percentage increases in males are calculated based on correcting for the levels of $\beta$-actin in each lane. Brain and spinal cord homogenates were made from six pairs of $\mathrm{C} 57 \mathrm{BL} / 6$ males and females, of which three pairs are shown in the blot. All six males show increases compared with the six females. This increase in total MBP expression correlates with the greater number of Olgs found in males compared with females. Although the total levels for the four isoforms are increased in males, the least abundant $21.5 \mathrm{kDa}$ isoform is increased $\sim 30-35 \%$ in females (Fig. 4). Similarly, CNPase protein levels (the sum of the 46 and $48 \mathrm{kDa}$ isoforms) are $\sim 160$ and $30 \%$ higher in spinal cords and brains of males compared with females (Fig. 4) (supplemental Fig. S1, available at www.jneurosci.org as supplemental material).

We also measured the levels of CA II and PLP transcripts in the brain based on our observations that the number of CA IIimmunostained cells and PLP/DM20 ${ }^{+}$cells are greater in males and also because the CA II immunostaining and the PLP/DM20 in situ hybridization product appears more intense in males compared with females. Real-time PCR was used to measure CA II and PLP transcripts in four pairs of 9-month-old C57BL/6J mice. The analytical sensitivity of real-time PCR was determined using a dilution series of CA II, PLP, and GAPDH cDNAs. The threshold cycle values of CA II and PLP mRNA in brain are normalized to GAPDH expression. All dilution samples fluoresce in the optimal exponential curve. The level of CA II mRNA is three times higher in males compared with females, and the level of PLP mRNA level is 1.7-fold higher (supplemental Figure S2, available at www.jneurosci.org as supplemental material).

\section{Glia cell proliferation}

The most likely explanation for the increase in density of Olgs in male white matter tracts is an increased proliferation in males or an increased cell death in females. We first examined BrdU incorporation in the corpus callosum of mice and rats at the same four ages used to quantify the number of Olgs. BrdU was injected once daily over 3 consecutive days, and the animals were killed 1 week after the first injection (Fig. $5 A-D$ ). A 1 week interval from the time of the first injection to the time of death allows sufficient time for postmitotic Olg progenitors to assume properties of mature glia. Surprisingly, the proliferation of glial cells in female corpora callosa is increased $\sim 100 \%$ (Fig. $6 A, B$ ) at the four different ages in the two different strains of mice and rats. Because the numbers of $\mathrm{BrdU}^{+}$cells are relatively infrequent, $\mathrm{BrdU}^{+}$cells were counted from the midline of the corpus callosum to its tail in the midventral half of the brain. Labeled cells were counted on the left and right sides of the corpus callosum and summed, six to eight consecutive sections were counted for each animal, and the mean was calculated.

The absolute number of $\mathrm{BrdU}^{+}$cells is approximately the same at 9 and 15 months in male and female mice but decreases to more than half in the 22-month-old mice (Fig. 6A). This finding most likely indicates that generation of new glia is decreased in older animals. Although only a small percentage of the total glia in the corpora callosa are $\mathrm{BrdU}^{+}$, the total number of newly generated glia is undoubtedly much higher than the numbers suggest. Cells incorporate BrdU only while they are in the $S$ phase of the cell cycle, $\sim 6-8 \mathrm{~h}$ for glial cells (Korr et al., 1973). Therefore, several injections spaced over $1 \mathrm{~d}$ would be needed to label all proliferating glia in a $24 \mathrm{~h}$ interval, and multiple injections over a prolonged period of time would be needed to estimate the total numbers of glia generated in adult rodents. One week after the BrdU injections, the labeled cells will be composed of postmitotic Olgs and astrocytes as well as Olg and astrocyte progenitors that will continue to proliferate (Sturrock, 1981). To determine the phenotype of the newly generated cells, sections were processed for BrdU and immunostained for astrocyte-specific (GFAP) (Fig. 5E) and oligodendrocyte-specific (CA II) (Fig. 5F) markers. The vast majority $(64 \%)$ of the $\mathrm{BrdU}^{+}$labeled cells are $\mathrm{GFAP}^{+}, 21 \%$ are $\mathrm{Ca} \mathrm{II}{ }^{+}$, and $15 \%$ are not double labeled (Fig. $5 H)$. These percentages indicate the cells that incorporate BrdU at the time of injections acquire the phenotype of mature macroglia. The BrdU ${ }^{+}$cells unstained for GFAP or CA II are probably cycling macroglial progenitor cells and microglia. No significant 


\section{Number of Labeled Cells $\times 10^{3}$ per $\mathrm{mm}^{2}$}

\section{Percent Increase Male/Female}

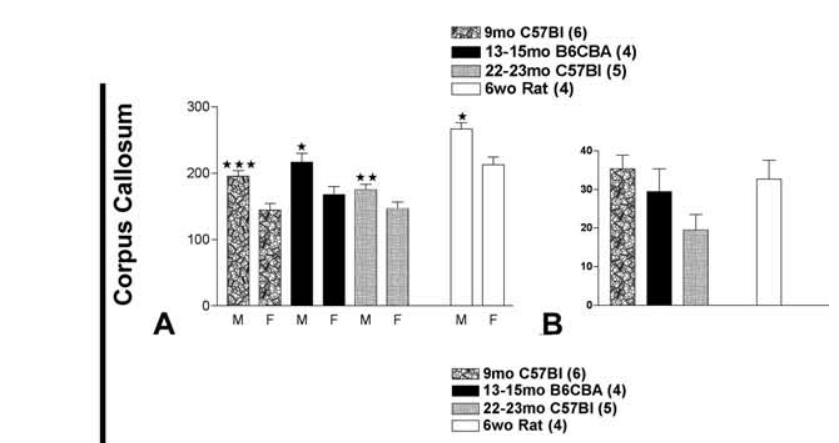

CA II

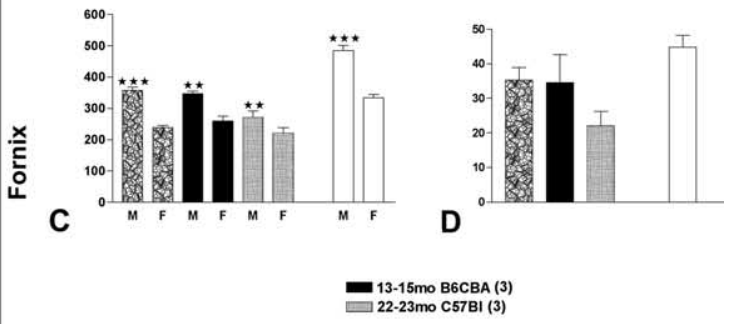

\section{Percent Differences in Protein Levels of MBP and CNPase of Males to Females}

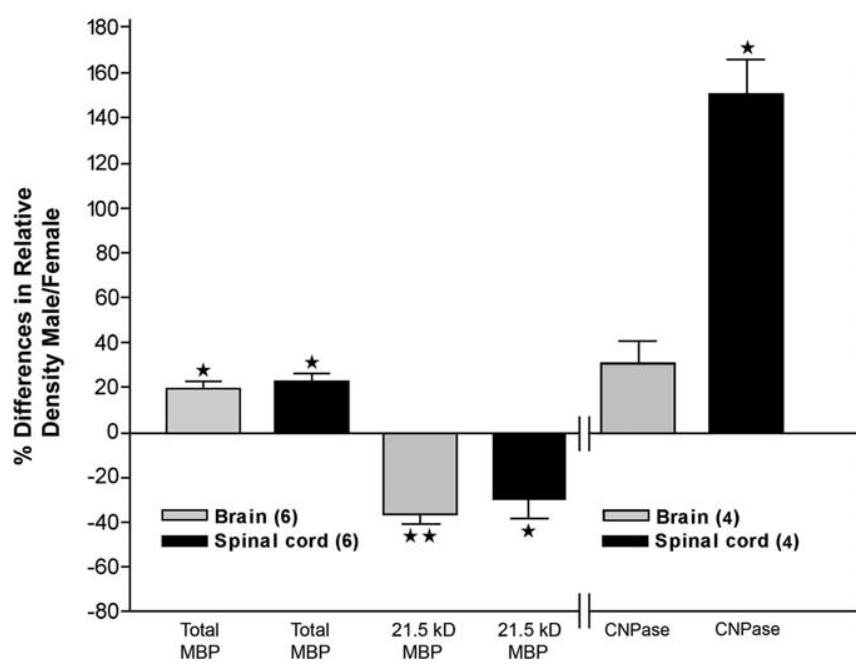

Figure 4. Percentage differences in relative densities of the four MBP isoforms in brain and spinal cord and CNPase in brains of 8- to 9-month-old C57BL/6 mice. The ratio of relative density of total MBP (sum of values for all 4 isoforms) and $\beta$-actin was calculated, and percentage differences in males were compared with females. The values for $21.5 \mathrm{kDa}$ isoforms were separately expressed because the ratio of $21.5 \mathrm{kDa}$ is greater in females than in males. Values are the mean \pm SEM of six male and six female pairs. The percentage difference in relative density of CNPase in the brain and spinal cord of four males compared with four females was similarly calculated as for MBP. One-sample $t$ test was used; ${ }^{*} p<0.05 ;{ }^{* *} p<0.001$.

differences in the percentages of $\mathrm{GFAP}^{+} / \mathrm{BrdU}^{+}$and $\mathrm{CA} \mathrm{II}{ }^{+} /$ $\mathrm{BrdU}^{+}$cells were found for males and females. Because the number of $\mathrm{BrdU}^{+}$cells is two times greater in females than in males, it is likely that approximately twice as many Olgs (and astrocytes) are generated in females compared with males.

\section{Glia cell death}

How is the number of Olgs decreased in females compared with males when the number of newly generated Olgs is increased in females compared with males? The most likely explanation is that Olg lifespan is decreased in females because of increased death. To determine the extent of cell death in male and female corpora callosa, brain sections were immunostained for cleaved caspase-3 activity (Fig. 7A-F). Cleaved caspase-3 is an excellent marker for apoptotic cells because this protease identifies dying glia in both early and late stages of apoptosis (Cerghet et al., 2001). Quantification of cleaved caspase-3 expression in corpora callosa of 13 - to 15-month-old B6CBA and 22-month-old C57BL/6J animals shows that the number of cells committed to die is significantly increased $60 \%$ in females compared with males $(p<0.0001)$. Some of these caspase- $3^{+}$cells are also immunostained for A007 (Fig. 7D-F), an Olg-specific marker (Bansal and Pfeiffer, 1992).

Our data show Olgs in females most likely have a shorter lifespan compared with males. If this is so, and assuming that these Olgs make myelin, myelin itself may also degenerate and, possibly, be regenerated at a greater rate in females than in males. The degradation of myelin has been indirectly monitored by examining levels of proteases abundant in myelin, especially $\mu$-calpain, because its activity is upregulated in multiple sclerosis (MS) (Shields et al., 1999; Schaecher et al., 2002) and in CNS injury (Ray et al., 1999). Most interestingly, the expression of total $\mu$-calpain (zymogen and active form) in spinal cords of 9-month-old C57BL/6 mice is twofold greater in females compared with males (Fig. 8). These results indicate higher activity of
Figure 3. Quantification of CA II-immunostained cells located in boxes shown for corpora callosa $(A)$, for fornices $(\boldsymbol{C})$, and for ventral columns of spinal cord $(\boldsymbol{E})$ and cells expressing PLP message in corpora callosa $(\boldsymbol{G})$, in fornices $(\boldsymbol{I})$, and in ventral columns of spinal cords $(\boldsymbol{K})$. Percentage increases in CA II cells in corpora callosa $(\boldsymbol{B})$, in fornices $(\boldsymbol{D})$, and in ventral columns of spinal cord $(\boldsymbol{F})$ and cells expressing PLP message in corpora callosa $(\boldsymbol{H})$, in fornices $(\boldsymbol{J})$, and in ventral columns of spinal cord $(\boldsymbol{L})$. Values represent mean \pm SEM of three to four sections per animal; number of animals counted at each age are in parentheses next to rodent strain. Two-tailed $t$ test comparison of male with female, assuming equal variance was used; ${ }^{*} p<0.05 ;{ }^{* *} p<0.001 ;{ }^{* * *} p<0.0001$. 

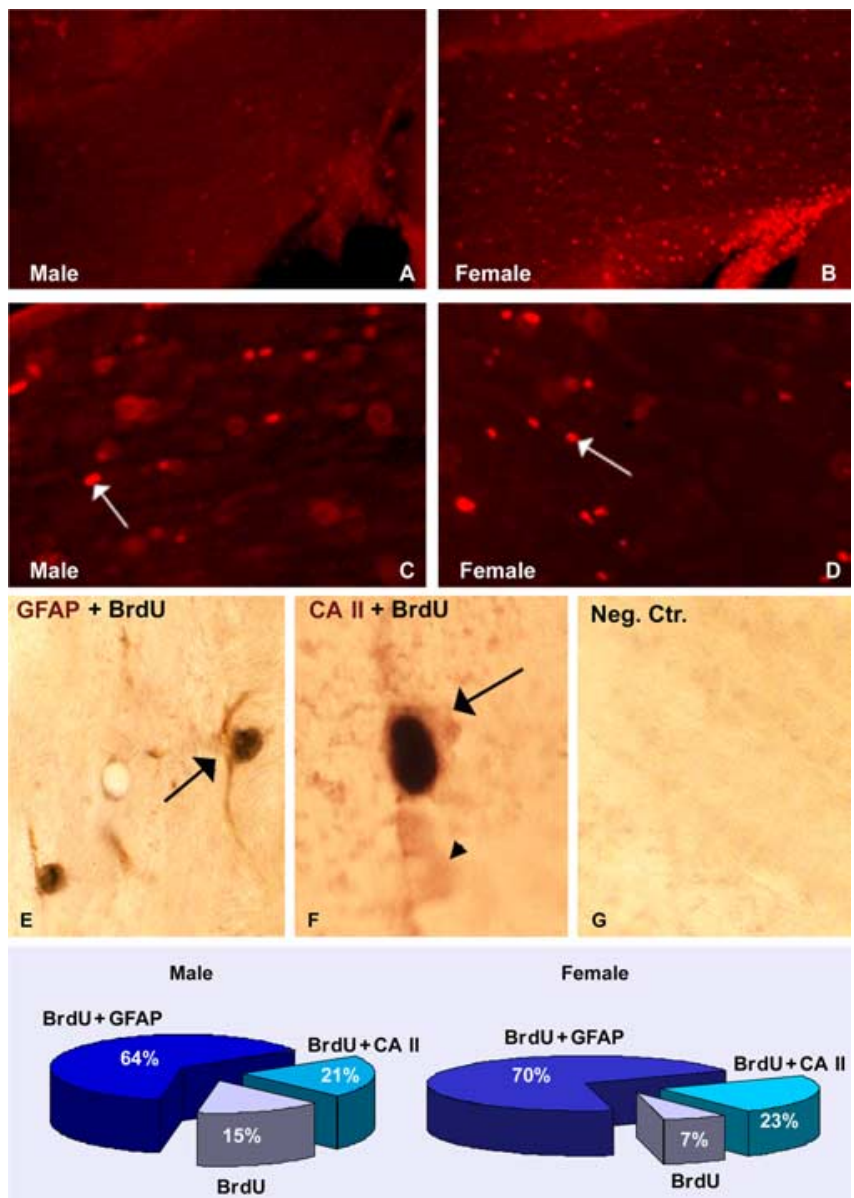

Neg. Ctr.

\section{D}
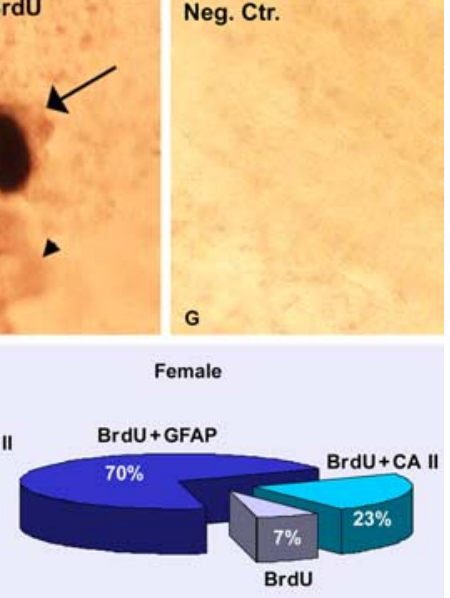

Figure 5. Generation of glial cells in corpus callosum. Representative low-magnification pictures at the level of the corpus callosum of 6 -week-old male $(\boldsymbol{A})$ and female $(\boldsymbol{B})$ CDIRS rats immunolabeled for BrdU. The large number of $\mathrm{BrdU}^{+}$cells in the subventricular zone of the female is a consistent finding at all ages. Higher magnification of BrdU ${ }^{+}$cells in corpora callosa of male $(\boldsymbol{C})$ and female $(\boldsymbol{D})$ rats. One injection of BrdU was given daily for $3 \mathrm{~d}$, and the animals were killed 1 week after the first injection. Double immunostaining of 9-month-old C57BL/6J corpus callosum for BrdU/GFAP $(\boldsymbol{E})$, BrdU/CAll $(\boldsymbol{F})$, or elimination of primary antibody $(\boldsymbol{G})$. GFAP ${ }^{+}$and $\mathrm{CA} \mathrm{II}^{+}$cells (arrows) are visualized in brown, and their BrdU ${ }^{+}$nuclei are visualized in black. The percentage of Olgs and astrocytes that are $\mathrm{BrdU}^{+}$is similar in males and females $(\boldsymbol{H})$.

at least one protease in CNS of females. Higher enzyme levels are also reflected by an increase in $\mu$-calpain message levels. With real-time PCR, we found that the message levels of $\mu$-calpain are increased $\sim 160 \%$ in females compared with males at 9 months. Using immunocytochemistry, $\mu$-calpain is localized in glial cells, some of which have the morphology of Olgs, located in the corpus callosum of both sexes (supplemental Fig. S3, available at www.jneurosci.org as supplemental material).

Because exogenous steroids and hormones play a role in sexual dimorphism of neurons and astroglia (Garcia-Segura et al., 1994; Mong et al., 1999), it is likely that they influence glial proliferation. The effects of hormones on Olg proliferation in vivo has not been studied, but, in experimental allergic encephalomyelitis (EAE), a model for multiple sclerosis, castration and/or exogenous hormone treatment shows that testosterone is protective (Voskuhl and Palaszynski, 2001). To test the effects of gonadal hormones on glial proliferation, males were castrated at 6 months and allowed to survive until 9 months. One week before death, the castrated mice were injected with BrdU following the same protocol used for normal mice; they were compared with unoperated males and females also injected with BrdU (Fig. 6). The number of $\mathrm{BrdU}^{+}$labeled cells in corpora callosa of castrated males is doubled compared with unoperated males and now matches the increased numbers in females (Fig. 9A). Cell counts of the number of CA II ${ }^{+}$cells in corpus callosum and fornix of castrated mice decreases compared with unoperated males and is intermediate to that of the unoperated males and females (Fig. 9). Thus, castration and the presumed reduction of gonadal hormones causes (1) increased proliferation of glia and (2) a reduction in the number of Olgs compared with unoperated males.

\section{Discussion}

The density of Olgs in corpus callosum, fornix, and spinal cord is increased in males compared with females

Differences in the number, shape, and size of neurons and astrocytes have been described previously in sexually dimorphic CNS structures, including the hypothalamus (Jacobson and Gorski, 1981; Mong et al., 1996) and hippocampus (Sherry et al., 1992; Markowska, 1999; Andrade et al., 2000; Barrera et al., 2001). However, sexual differences in numbers of neuroglial cells and myelin components in white matter tracts that emerge from these regions have never been investigated. The literature hints, however, that white matter is sexually dimorphic. The area of the male corpus callosum in rodents (Berrebi et al., 1988; Bimonte et al., 2000 ) is $\sim 10 \%$ larger than in females. Males also have more myelinated fibers in the genu and in the splenium of the corpus callosum than females (Mack et al., 1995; Nuñez et al., 2000). These studies imply that the average axonal diameter is larger and myelin sheaths are correspondingly thicker in males than in females. Accordingly, the amount of myelin should be greater in males than in females, and, assuming that an individual Olg is limited in the amount of myelin it forms, it also follows that more Olgs should be present in males.

In a previous in vivo study of jimpy mice (Knapp et al., 1990) and in studies using male and female rodents in this laboratory, we suspected differences in glial cell numbers between the sexes. To confirm our suspicions, we counted Olgs within a defined volume of white matter using two different histological methods. Both CA II immunocytochemistry and PLP in situ hybridization gave similar results in three different white matter tracts (corpus callosum, fornix, and spinal cord). In all three regions and at four different time points that range from 1.5- to 23-month-old rodents, the density of Olgs is $\sim 30 \%$ greater in males compared with females. This difference is most striking in 1.5-month-old rats when males had $40 \%$ more Olgs compared with females. The difference in density of Olgs between the sexes is much greater than we anticipated and was so dramatic that it was possible to determine the rodents' sex from blinded sections that were immunostained for CA II or processed for PLP in situ hybridization.

\section{Olg-specific markers are increased in males compared with females}

Message levels for PLP and CA II, determined by real-time PCR, are 170 and $320 \%$ higher, respectively, in males compared with females. The level for all MBP isoforms, determined by Western blots, show a $20 \%$ greater level in males compared with females. However, the least abundant of the MBP isoforms, $21.5 \mathrm{kDa}$, is $355 \%$ greater in females compared with males. Although all four MBP isoforms are membrane associated, the $21.5 \mathrm{kDa}$ isoform is also transported to the nucleus (Staugaitis et al., 1990), raising the 
A

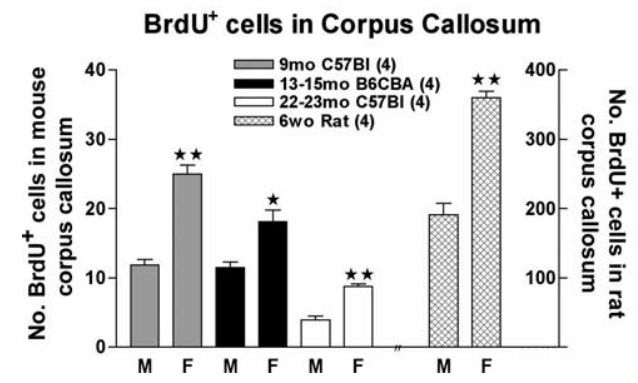

B

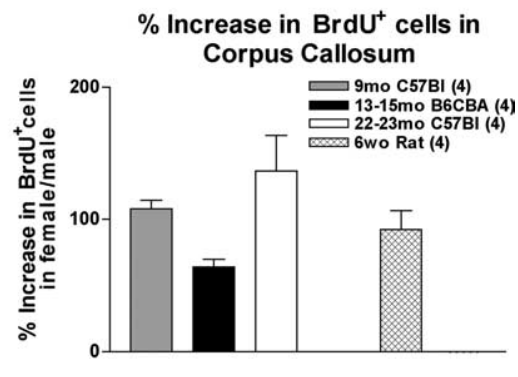

Figure 6. Total number of BrdU ${ }^{+}$glia in corpora callosa at different ages and in different rodent strains $(\boldsymbol{A})$. The number of $\mathrm{BrdU}^{+}$cells is the sum of both sides of the corpora callosa at the level of the striatum. Rats at 6 weeks have nearly 10 times the number of BrdU ${ }^{+}$cells as the mouse. The percentage increase in female rodents is approximately two times greater at all four ages $(\boldsymbol{B})$ in mice and rats. Values represent mean $\pm \mathrm{SEM} \mathrm{of} \mathrm{BrdU}^{+}$cells in corpora callosa from six to eight sections per animal, and number of animals at each age is in parentheses. Two-tailed $t$ test assuming equal variances was used to compare male with female for each strain; ${ }^{*} p<0.05 ;{ }^{* *} p<0.0001$.
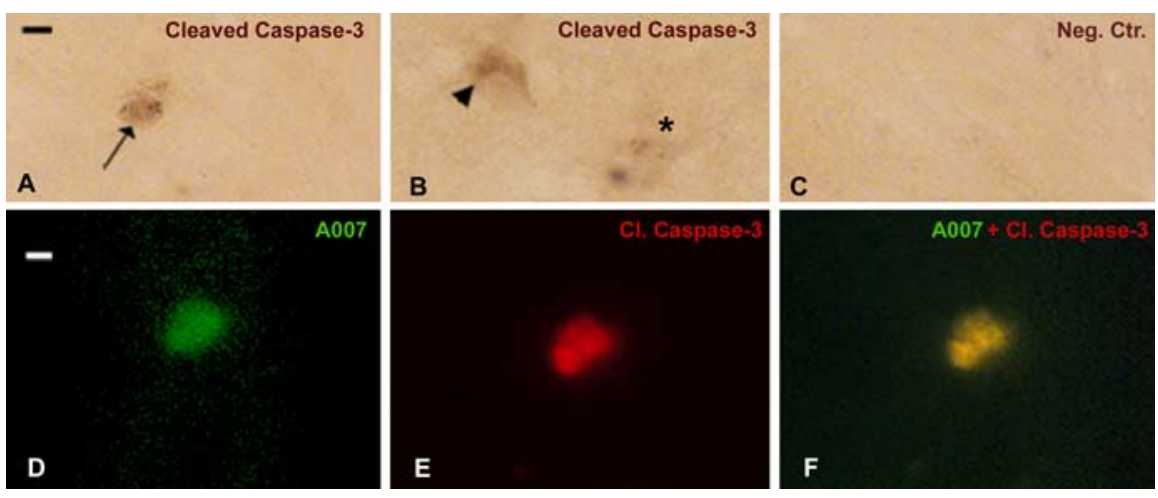

Figure 7. Examples of cleaved caspase- $3^{+}$cells in corpus callosum visualized with $\mathrm{DAB}(\boldsymbol{A}, \boldsymbol{B})$. An apoptotic glia in an advanced stage of degeneration shows cleaved caspase- 3 immunostaining in the nucleus (arrow); an apoptotic cell in an early stage of degeneration shows cleaved caspase- 3 immunostaining in the cytoplasm (arrowhead) and a cell with wrinkled membrane and light vacuoles inside (asterisk); elimination of primary antibody shows no staining (C). Double immunostaining with the A007 Olg-specific antibody $(\boldsymbol{D})$ and cleaved caspase-3 antibody $(\boldsymbol{E})$ shows that 0 lgs are apoptotic $(\boldsymbol{F})$. Scale bars, $5 \mu \mathrm{m}$.

\section{Western Detection of $\mu$-Calpain in Spinal Cord}

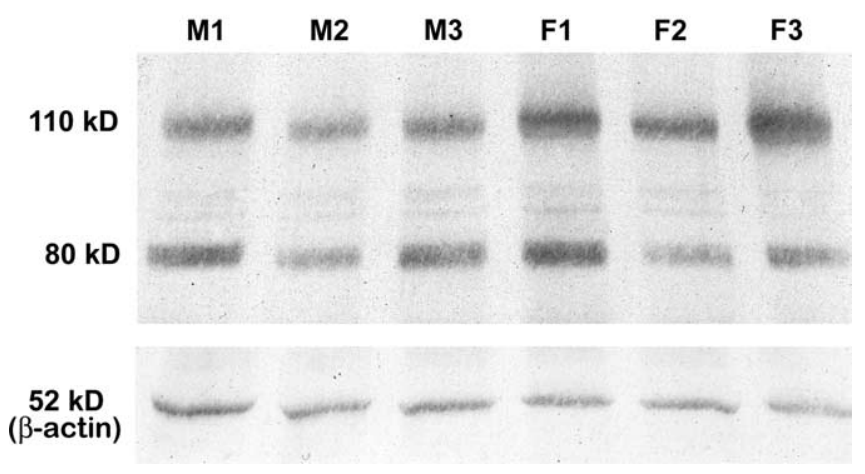

Figure 8. Western blot of $\mu$-calpain zymogen (110 kDa) and its cleaved form ( $80 \mathrm{kDa})$ in brains of three pairs of $[57 \mathrm{BL} / 6 \mathrm{~J}$ mice.

question of whether it is involved in transcriptional regulation. CNPase protein was increased 30 and $160 \%$ in the brain and spinal cord. Because such large differences of Olg proteins and messages between the sexes were found in whole-brain homogenates, these data suggest that sexual dimorphism of Olgs and myelin probably exists across the whole brain.
Oligodendrocyte proliferation and cell death is increased in females compared with males

The differences in Olg density between sexes could be explained by an increase in production of Olgs in males at some stage of their life or by an increase of Olg death in females. To our surprise, formation of newly generated glia in corpus callosum is two times greater in females than in males from late postnatal to aged animals. Double immunostaining shows that $85-93 \%$ of newly generated cells mature into astrocytes and Olgs. Because formation of new Olgs is greater in females but their total number is less than in males, a higher percentage of Olgs must die in females compared with males. Active caspase- $3^{+}$cells reveal that glial death in corpus callosum is $50 \%$ greater in female versus male. Double immunostaining reveals that some caspase- $3^{+}$cells are Olgs but many were not positive for Olg markers (Cerghet et al., 2001). Because proliferation and cell death are increased in females, Olgs in females should have a shorter lifespan and turn over more rapidly than male Olgs.

Assuming that some dying Olgs had formed myelin sheaths, we predict that more myelin should be degraded in females. Using Western blot analysis, $\mu$-calpain expression, a protease implicated in degradation of myelin (Shields et al., 1999; Schaecher et al., 2002), is two times greater in females compared with males in 9-month-old spinal cord and brain. Using real-time PCR, transcription of $\mu$-calpain is also $\sim 160 \%$ higher in females compared with males at 9 months. Using immunocytochemistry, a $\mu$-calpain antibody strongly stained randomly distributed Olgs in white matter but also weakly stained most neurons. This finding suggests that the higher levels of $\mu$-calpain in females affects many CNS cell types, and, because the active form is also higher in females than in males, it suggests that degradation of proteins is greater in females.

The differences in levels of $\mu$-calpain transcription and translation are directly relevant to MS. $\mu$-Calpain is one of several calcium-activated proteases implicated in MS and EAE. Millicalpain ( $\mathrm{m}$-calpain) expression is likewise increased in demyelinating diseases, spinal cord injury (Ray et al., 1999), and Parkinson's disease (Shields et al., 1999). In light of our findings, m-calpain, other proteases, and calpain inhibitors are likely different between sexes. Interestingly, myelin in normal-appearing white matter (NAWM) of MS patients degrades faster than in controls, Alzheimer's, and Parkinson's patients (Moscarello et al., 1994). Using biochemical, mass spectrometric, and electron microscopic techniques, these investigators reported that NAWM in MS patients retains many features of "immature" myelin. This immature myelin is found outside the plaques in NAWM and raises the interesting question of whether this immature myelin is more vulnerable to attack by the immune system than mature myelin. 
A

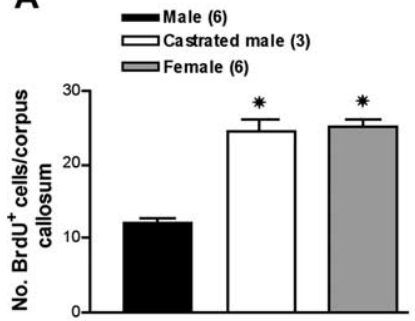

B

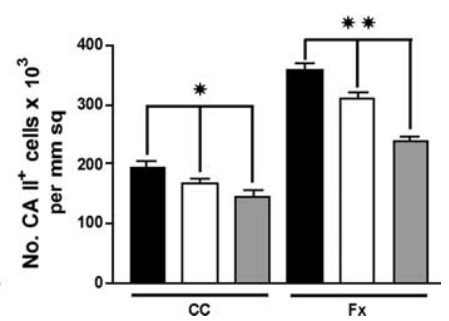

Figure 9. The number of $\mathrm{BrdU}^{+}$cells in corpora callosa of castrated males matches the number in females at 9 months $(\boldsymbol{A})$. Males were castrated at 6 months and injected daily with BrdU over $3 \mathrm{~d}$ beginning 1 week before death at 9 months. The numbers of BrdU ${ }^{+}$cells in unoperated males and females is the same data as that shown in the 9 month study (Fig. 6). The number of newly generated $\mathrm{BrdU}^{+}$cells in castrated males is two times compared with wildtype males. Values represent mean \pm SEM of BrdU ${ }^{+}$cells in six sections per animal of 9-month-old C57BL/6J. Two-tailed $t$ test assuming equal variances was used to compare male with castrated male and female; ${ }^{*} p<0.001$. The number of $\mathrm{CA}{ }^{+}$cells in corpus callosum and fornix of castrated mice is decreased compared with unoperated males $(\boldsymbol{B})$. The decrease in CA $\mathrm{II}^{+}$Olgs is approximately halfway between the values for unoperated males and females. Values represent mean \pm SEM of $\mathrm{CA} \|^{+}$cells. One-way ANOVA was used to compare each group within the corpus callosum $(C \mathrm{C})$ and fornix $(\mathrm{Fx}) ;{ }^{*} p<0.01 ;{ }^{* *} p<0.0001$.

\section{The role of hormones in sexual dimorphism of oligodendrocytes}

Very few studies report the influence of sex hormones/hormonal receptors on Olgs. Oligodendrocytes synthesize progesterone from pregnenolone (Zwain and Yen, 1999), and progesterone administration in vivo (Alonso, 2000) and in vitro (MarinHusstege et al., 2004; Takao et al., 2004) has various effects on Olg proliferation and maturation. In contrast to the intrinsic synthesis of progesterone by Olgs, they do not express enzymes necessary for synthesis of estradiol or testosterone (Zwain and Yen, 1999). However, Olgs express these receptors (Jung-Testas et al., 1994; Finley and Kritzer, 1999; Zhang et al., 2004), and, in tissue culture, the proliferation, maturation, and death of Olgs varies depending on concentrations of estrogen (Marin-Husstege et al., 2004; Takao et al., 2004). Estrogen appears to enhance survival of cultured, mature Olgs when exposed to cytotoxic compounds (Takao et al., 2004). However, our in vivo studies indicate that Olg death is increased in females compared with males, but the differences between the in vitro and in vivo studies may be attributable to interactions of multiple hormones and growth factors in vivo that affect Olg survival. Understanding the action of sex hormones in Olgs is even more complicated in vivo because expression of progesterone receptors in brain can be induced by estrogen in females (Jung-Testas et al., 1991) or testosterone in males (Quadros et al., 2002).

The differences in morphological and biochemical composition of Olgs and myelin between the sexes is partially regulated by exogenous hormones. Castration of males 3 months before death reduces the level of newly generated glia in white matter tracts of males to levels in females, and castration also reduces the density of Olgs compared with unoperated males. Although we did not compare cell death in castrated male mice with normal males, the only explanation that accounts for increased glial proliferation and a smaller density of Olgs in castrated males is increased glial death. Our findings demonstrate that alterations in primary sex hormones, presumably testosterone, have dramatic effects on proliferation and cell death of Olgs. Although different neural cells are capable of synthesizing both male and female hormones, castration overrides any attempts by glia and neurons to compensate for the loss of exogenously produced androgens. In a differ- ent vein, the influence of sex hormones has been studied in experimental models of MS by either castration or ovariectomy. Castration increased severity of the disease in EAE (Bebo et al., 1996), but ovariectomy had no effect in reducing the disease severity (Voskuhl and Palaszynski, 2001). These studies suggest that androgens are more protective than estrogens in ameliorating EAE. The lowest levels of serum testosterone in women with MS correlate with the severity of the disease, another indication that androgens are protective (Tomassini et al., 2005). Our in vivo CNS studies also demonstrate that glia in the CNS is one axis affected by androgen withdrawal but also raises an intriguing possibility of a direct link between Olg and myelin degeneration and induction of an autoimmune response.

Although most researchers believe that the composition of myelin in MS patients is normally structured, others argue that MS patients have structurally immature myelin (Moscarello et al., 1994). Is the immature myelin the result of a developmental defect that persists into adulthood, or is it a consequence of altered turnover of Olgs and myelin? The presumably thinner myelin sheaths in females may have a different protein composition than thicker sheaths in males and this, combined with a greater turnover of Olgs in females, may lead to more myelin breakdown products. Increased myelin fragments released into the CSF or intracellular space may more easily trigger an immune response. Although any causal relationship between the sexual dimorphism of Olgs and the increased incidence of MS in females is a topic for additional study, this study shows for the first time dramatic differences in functional properties of Olgs in males and females and undoubtedly shows the necessity of using proper gender controls when performing experimental studies of the brain.

\section{References}

Alonso G (2000) Prolonged corticosterone treatment of adult rats inhibits the proliferation of oligodendrocyte progenitors present throughout white and gray matter regions of the brain. Glia 31:219-231.

Andrade JP, Madeira MD, Paula-Barbosa MM (2000) Sexual dimorphism in the subiculum of the rat hippocampal formation. Brain Res 875:125-137.

Bansal R, Stefansson K, Pfeiffer SE (1992) Proligodendroblast antigen (POA), a developmental antigen expressed by AOO7/O4-positive oligodendrocyte progenitors prior to the appearance of sulfatide and galactocerebroside. J Neurochem 58:2221-2229.

Barrera A, Jimenez L, Gonzalez GM, Montiel J, Aboitiz F (2001) Dendritic structure of single hippocampal neurons according to sex and hemisphere of origin in middle-aged and elderly human subjects. Brain Res 906:31-37.

Bebo Jr BF, Vandenbark AA, Offner H (1996) Male SJL mice do not relapse after induction of EAE with PLP 139-151. J Neurosci Res 45:680-689.

Benjamins JA, Morell P (1978) Proteins of myelin and their metabolism. Neurochem Res 3:137-174.

Berrebi AS, Fitch RH, Ralphe DL, Denenberg JO, Friedrich Jr VL, Denenberg VH (1988) Corpus callosum: region-specific effects of sex, early experience and age. Brain Res 438:216-224.

Bessert DA, Skoff RP (1999) High-resolution in situ hybridization and TUNEL staining with free-floating brain sections. J Histochem Cytochem 47:693-702.

Bimonte HA, Fitch RH, Denenberg VH (2000) Neonatal estrogen blockade prevents normal callosal responsiveness to estradiol in adulthood. Brain Res Dev Brain Res 122:149-155.

Cerghet M, Bessert DA, Nave KA, Skoff RP (2001) Differential expression of apoptotic markers in jimpy and in Plp overexpressors: evidence for different apoptotic pathways. J Neurocytol 30:841-855.

Daston G, Lamar E, Olivier M, Goulding M (1996) pax-3 is necessary for migration but not differentiation of limb muscle precursors in the mouse. Development 122:1017-1027.

Finley SK, Kritzer MF (1999) Immunoreactivity for intracellular androgen receptors in identified subpopulations of neurons, astrocytes and oligodendrocytes in primate prefrontal cortex. J Neurobiol 40:446-457. 
Fitch RH, Berrebi AS, Cowell PE, Schrott LM, Denenberg VH (1990) Corpus callosum: effects of neonatal hormones on sexual dimorphism in the rat. Brain Res 51:111-116.

Garcia-Segura LM, Chowen JA, Parducz A, Naftolin F (1994) Gonadal steroids as promoters of neuro-glial plasticity. Prog Neurobiol 4:279-307.

Ghandour MS, Skoff RP (1991) Double-labeling in situ hybridization analysis of mRNAs for carbonic anhydrase II and myelin basic protein: expression in developing cultured glial cells. Glia 4:1-10.

Ghandour MS, Langley OK, Vincendon G, Gombos G (1979) Double labeling immunohistochemical technique provides evidence of the specificity of glial cell markers. J Histochem Cytochem 27:1634-1637.

Goldstein JM, Seidman LJ, Horton NJ, Makris N, Kennedy DN, Caviness Jr VS, Faraone SV, Tsuang MT (2001) Normal sexual dimorphism of the adult brain assessed by in vivo magnetic resonance imaging. Cereb Cortex 11:490-497.

Guillery RW, Herrup K (1997) Quantification without pontification: choosing a method for counting objects in sectioned tissues. J Comp Neurol 386:2-7.

Gur RC, Turetsky BI, Matsui M, Yan M, Bilker W, Hughett P, Gur RE (1999) Sex differences in brain gray and white matter in healthy young adults: correlations with cognitive performance. J Neurosci 19:4065-4072.

Harasty J, Double KL, Halliday GM, Kril JJ, McRitchie DA (1997) Language-associated cortical regions are proportionally larger in the female brain. Arch Neurol 54:171-176.

Jacobson CD, Gorski RA (1981) Neurogenesis of the sexually dimorphic nucleus of the preoptic area in the rat. J Comp Neurol 196:519-529.

Jalabi W, Cerghet M, Skoff RP, Ghandour MS (2003) Detection of oligodendrocytes in tissue sections using PCR synthesis of digoxigenin-labeled probes. J Histochem Cytochem 51:913-919.

Jung-Testas I, Renoir JM, Gase JM, Baulieu EE (1991) Estrogen-inducible progesterone receptor in primary cultures of rat glial cells. Exp Cell Res 193:12-19.

Jung-Testas I, Schumacher M, Robel P, Baulieu EE (1994) Actions of steroid hormones and growth factors on glial cells of the central and peripheral nervous system. J Steroid Biochem Mol Biol 48:145-154.

Kim JH, Juraska JM (1997) Sex differences in the development of axon number in the splenium of the rat corpus callosum from postnatal day 15 through 60. Brain Res Dev Brain Res 102:77-85.

Knapp PE, Dutta S, Skoff RP (1990) Differences in levels of neuroglial cell death in jimpy male mice and carrier females. Dev Neurosci 12:145-152.

Knapp PE, Benjamins JA, Skoff RP (1996) Epigenetic factors up-regulate expression of myelin proteins in the dysmyelinating jimpy mutant mouse. J Neurobiol 29:138-150.

Korr H, Schultze B, Maurer W (1973) Autoradiographic investigations of glial proliferation in the brain of adult mice. I. The DNA synthesis phase of neuroglia and endothelial cells. J Comp Neurol 150:169-176.

Mack CM, Boehm GW, Berrebi AS, Denenberg VH (1995) Sex differences in the distribution of axon types within the genu of the rat corpus callosum. Brain Res 697:152-160.

Marin-Husstege M, Muggironi M, Raban D, Skoff RP, Casaccia-Bonnefil P (2004) Oligodendrocyte progenitor proliferation and maturation is differentially regulated by male and female sex steroid hormones. Dev Neurosci 26:245-254.

Markowska AL (1999) Sex dimorphisms in the rate of age-related decline in spatial memory: relevance to alterations in the estrous cycle. J Neurosci 19:8122-8133.

Mong JA, Kurzweil RL, Davis AM, Rocca MS, McCarthy MM (1996) Evi- dence for sexual differentiation of glia in rat brain. Horm Behav 30:553-562.

Mong JA, Glaser E, McCarthy MM (1999) Gonadal steroids promote glial differentiation and alter neuronal morphology in the developing hypothalamus in a regional specific manner. J Neurosci 19:1464-1472.

Moscarello MA, Wood DD, Ackerley C, Boulias C (1994) Myelin in multiple sclerosis is developmentally immature. J Clin Invest 94:146-154.

Nave KA, Bloom FE, Milner RJ (1987) A single nucleotide difference in the gene for myelin proteolipid protein defines the jimpy mutation in mouse. J Neurochem 49:1873-1877.

Nottebohm F, Arnold AP (1976) Sexual dimorphism in vocal control areas of the songbird brain. Science 194:211-213.

Nuñez JL, Nelson J, Pych JC, Kim JHY, Juraska JM (2000) Myelination in the splenium of the corpus callosum in adult male and female rats. Dev Brain Res 120:87-90.

Quadros PS, Lopez V, De Vries GJ, Chung WC, Wagner CK (2002) Progesterone receptors and the sexual differentiation of the medial preoptic nucleus. J Neurobiol 51:24-32.

Ray SK, Shields DC, Saido TC, Matzelle DC, Wilford GG, Hogan EL, Banik NL (1999) Calpain activity and translational expression increased in spinal cord injury. Brain Res 816:375-380.

Roof RL (1993) Neonatal exogenous testosterone modifies sex difference in radial arm and Morris water maze performance in prepubescent and adult rats. Behav Brain Res 53:1-10.

Schaecher K, Rocchini A, Dinkins J, Matzelle DD, Banik NL (2002) Calpain expression and infiltration of activated cells in experimental allergic encephalomyelitis over time: increased calpain activity begins with onset of disease. J Neuroimmunol 129:1-9.

Schlaepfer TE, Harris GJ, Tien AY, Peng L, Lee S, Pearlson GD (1995) Structural differences in the cerebral cortex of healthy female and male subjects: a magnetic resonance imaging study. Psychiatry Res 61:129-135.

Sherry DF, Jacobs LF, Gaulin SJ (1992) Spatial memory and adaptive specialization of the hippocampus. Trends Neurosci 15:56-57.

Shields DC, Schaecher KE, Saido TC, Banik NL (1999) A putative mechanism of demyelination in multiple sclerosis by a proteolitic enzyme, calpain. Proc Natl Acad Sci USA 96:11486-11491.

Sorg BA, Smith MM, Campagnoni AT (1987) Developmental expression of the myelin proteolipid protein and basic protein mRNAs in normal and dysmyelinating mutant mice. J Neurochem 49:1146-1154.

Staugaitis SM, Smith PR, Colman DR (1990) Expression of myelin basic protein isoforms in nonglial cells. J Cell Biol 110:1719-1727.

Sturrock RR (1981) Electron microscopic evidence for mitotic division of oligodendrocytes. J Anat 132:429-432.

Takao T, Flint N, Lee L, Ying X, Merrill J, Chandross KJ (2004) 17 Betaestradiol protects oligodendrocytes from cytotoxicity induced cell death. J Neurochem 89:660-673.

Tomassini V, Onesti E, Mainero C, Giugni E, Paolillo A, Salvetti M, Nicolettit F, Pozzilli C (2005) Sex hormones modulate brain damage in multiple sclerosis: MRI evidence. J Neurol Neurosurg Psychiatry 76:272-275.

Voskuhl RR, Palaszynski K (2001) Sex hormones in experimental autoimmune encephalomyelitis: implications for multiple sclerosis. The Neuroscientist 7:258-270.

Zhang Z, Cerghet M, Mullins C, Williamson M, Bessert D, Skoff R (2004) Comparison of in vivo and in vitro subcellular localization of estrogen receptors alpha and beta in oligodendrocytes. J Neurochem 89:674-684.

Zwain IH, Yen SS (1999) Neurosteroidogenesis in astrocytes, oligodendrocytes, and neurons of cerebral cortex of rat brain. Endocrinology 140:3843-3852. 